\title{
Magnetic Field Sensor Using Asymmetric Giant Magnetoimpedance Effect Created by Micro Magnets
}

\section{Tekin Izgi ( $\nabla$ tekin.izgi@inonu.edu.tr)}

Inonu Universitesi https://orcid.org/0000-0002-4489-905X

\section{Pektas}

Inonu University: Inonu Universitesi

\section{V.S. Kolat}

Inonu University: Inonu Universitesi

N. Bayri

İnönü Üniversitesi: Inonu Universitesi

S. Atalay

Inonu University: Inonu Universitesi

\section{Original Research}

Keywords: Asymmetry, magnetoimpedance, magnetic field sensor

Posted Date: February 12th, 2021

DOI: https://doi.org/10.21203/rs.3.rs-181044/v1

License: (c) (1) This work is licensed under a Creative Commons Attribution 4.0 International License. Read Full License 


\section{Abstract}

A magnetic field sensor was developed using asymmetric giant magnetoimpedance (AGMI) effect. Amorphous ferromagnetic $\left(\mathrm{Fe}_{0.06} \mathrm{Co}_{0.94}\right){ }_{72.5} \mathrm{Si}_{12.5} \mathrm{~B}_{15}$ wires were used in this study. The $2 \mathrm{~cm}$ long wire showed about $88 \%$ and the $7 \mathrm{~cm}$ long wire showed about $197 \%$ giant magnetoimpedance effect. When two micro magnets were placed $1 \mathrm{~cm}$ away from the ends of the wire, a distortion in two peak shapes of the GMI curve was observed and asymmetry was created by micro magnets and $7 \mathrm{~cm}$ long wire showed about $148 \%$ AGMI effect. A simple and a new approach was designed to develop a magnetic field sensor, in the design circuit two signal generators were used to arrange linearity and dc offset in the output signal. The circuit output showed good linearity and zero hysteresis at $\pm 250 \mathrm{~A} / \mathrm{m}$ and $\pm 50 \mathrm{~A} / \mathrm{m}$ magnetic field regions for $2 \mathrm{~cm}$ wires long and $7 \mathrm{~cm}$ wires long, respectively.

\section{Introduction}

GMI is defined as a significant change in the impedance of certain soft ferromagnetic materials (amorphous or nanocrystalline wires or ribbons, films and multi-layered structures) when subjected to an external magnetic field [1-6]. Such a characteristic already has great potential for magnetic sensor applications. The very high sensitivity of such sensors combined with a low cost, low consumption and a small size suggests that these devices have a certain future in the production of high sensitivity magnetometers or sensors of physical quantities $[1,7]$. The first research around GMI focused on understanding the phenomenon [8-12] and studying the possibilities of improving the sensitivity of materials [13-14]. It has been reported that different parameters can maximize GMI [13-15]. These parameters are related to the softness of the material. The material must, therefore, have small magnetostriction, a small coercivity, a low value of magnetic anisotropy, high saturation magnetization and high permeability. Since these sensors measure the magnetic field, they can, therefore, be used in applications for measuring electric current, linear or angular position and force [1,9]. These sensors, therefore, find their place in a wide range of applications such as automotive, high-density magnetic recording, biomedical, space, military, security and various research applications [16-21].

The impedance of soft magnetic materials changes gradually around the zero magnetic field and this leads to unfavorable GMI sensors for the many applications [22-23]. Whereas, the asymmetric field dependence of the impedance may be an option to solve this problem and the AGMI effect can be defined as the distortion of the symmetry of the Ml curve by changing the external or internal parameters [22-23]. Thus, a sharper and even linear change in impedance value can be obtained around zero magnetic field.

The AGMI effect has also been found in micro and glass-covered wires, multilayered magnetic wires, films, multilayered films and ribbons [24-35]. AGMI effect, which has recently played an important role in the development of weak magnetic field sensors, has attracted great interest [36-41]. The asymmetric magneto-impedance effect first emerged by passing the dc bias current superimposed on the ac drive current through twisted Co-based amorphous wires [33]. In addition, asymmetric giant magnetoimpedance was measured in Co-based amorphous wire under heat treatment under a circular 
area produced by dc bias current [34]. The circular bias area supports the wall movement in one direction while supporting it in another direction, and asymmetric behaviour is observed in proportion to the applied bias current. Asymmetric magneto-impedance was also observed in the Co-based amorphous strip heated under a low magnetic field in the air [35].

It has been reported that AGMI can be obtained by applying a dc current and linearization could be realized. In this case, if two elements fed with opposite dc current are applied to the differential amplifier together, a linear output can be obtained as a function of the magnetic field [35]. However, applying a dc bias current increases power consumption and requires extra device usage. Recently, instead of using a dc bias current we used micro magnets to obtain AGMI and studied the effect of ac driving current frequency and the mechanism of AGMI due to micro magnets [42-43]. In this study, we report a magnetic field sensor using AGMI curves obtained micro magnets.

\section{Development Of Agmi Magnetic Field Sensor}

\section{A. AGMI Measurements}

Amorphous ferromagnetic $\left(\mathrm{Fe}_{0.06} \mathrm{Co}_{0.94}\right){ }_{72.5} \mathrm{Si}_{12.5} \mathrm{~B}_{15}$ wires were used in this study. The wire has a nearly zero magnetostriction and it is supplied by Unitika Company. The wire with a diameter of $125 \mu \mathrm{m}$ was cut for measurements of 2, 4.5 and $7 \mathrm{~cm}$ in length. Electrical connections were made using silver conductive paint. Agilent 4294A impedance analyser was used for MI measurements at $100 \mathrm{kHz}$. Earth's magnetic field was cancelled out using Helmholtz coils. The applied magnetic field was swept from $-H_{\max }$ to $+H_{\max }$ and then to $-H_{\max }$ in all measurements. The GMI ratio as a function of the DC applied magnetic field $H$ was defined as $\Delta Z / Z(\%)=100 \times\left[Z(H)-Z\left(H_{\max }\right)\right] / Z\left(H_{\text {max }}\right)$, where the maximum applied field $H_{\max }$ was taken to be $+3000 \mathrm{~A} / \mathrm{m}$ or $-3000 \mathrm{~A} / \mathrm{m}$.

Figure 1 shows the Ml curve of wires 2 and $7 \mathrm{~cm}$ long at $100 \mathrm{kHz}$ driving current frequency. The Ml curves have a single peak shape and the results are in agreement with those previously found. 2 micro magnets were placed $1 \mathrm{~cm}$ from the end of the wire to form AGMI (Fig.2). NdFeB magnets supplied from China have a maximum energy product of $406 \mathrm{~kJ} / \mathrm{m}^{3}$. Magnets have a length of $1 \mathrm{~mm}$ and a diameter of 300 $\mu \mathrm{m}$. Fig. 3 presents the AGMI curves of wires with different lengths with two micro magnets, which are placed at $1 \mathrm{~cm}$ away from the ends of the wire as shown in Fig.2. Amorphous wires were kept at a distance of $1.5 \mathrm{~cm}$ from each other in all measurements to minimize the interaction between amorphous wires and magnets. Of course, there may still be some wire interactions, but since the purpose of the study is not in this direction, these interactions have not been studied in detail. It was found that changing of direction of magnets leads to change in the asymmetry direction in the AGMI curves, but no difference in the behaviour of the curve was observed. Basically, we have used this property of AGMI to design a magnetic field sensor.

The observed AGMI effect can be ascribed to a non-uniform bias field created by micro magnets. The bias field changes the static magnetization distribution and the effective permeability in the wire. In the 
presence of the bias field, the field dependence of the permeability becomes asymmetric, and the AGMI is detected, details are given in [42-43].

\section{B. Sensor Circuit Design and Results}

AGMI magnetic field sensor was developed using amorphous ferromagnetic wire and measurement circuit. Firstly, the sinusoidal signal with a frequency of $100 \mathrm{kHz}$ and $1.2 \mathrm{~V}$ amplitude was applied to the ends of the $7 \mathrm{~cm}$ wires, which were attached to two micro magnets as shown in figure 2, and then measurements were made for the wires with the opposite direction of the magnets under the same conditions. The ac signal obtained between the two ends of the wire was applied to the peak detector and the dc output signal was obtained from there. As can be seen in Figure 4, AGMI curves were obtained as a function of the magnetic field. In general, the shape of the curves was found to be compatible with the AGMI curves given in figure 3. After one of these two curves was inverted, the addition of these two curves was done by computer and as seen in Figure 5, a linear curve was obtained as a function of the magnetic field.

A simple circuit was designed to perform the above-mentioned process. The circuit consists of two signal generators, two peak detectors and one differential amplifier. The circuit diagram is given in figure 6 . One of the amorphous wires with $7 \mathrm{~cm}$ length in the circuit is attached to magnets as in figure $2 \mathrm{a}$ and in the other, as in figure 2b. Fig. 7 shows the effect of driving frequency and its amplitude on the output of the circuit $\left(\mathrm{V}_{\text {out }}\right)$. As can be seen from the curve (a) in Fig. 7, $\mathrm{V}_{\text {out }}$ does not show a linear change exactly as a function of the magnetic field when a signal with values of $100 \mathrm{kHz}$ and $1 \mathrm{~V}$ is applied from the signal generators 1 and 2. In addition, when the amplitude of the signal applied from the signal generator 2 was increased to $1.2 \mathrm{~V}$, a shift in $\mathrm{V}_{\text {out }}$ was observed (curve $\mathrm{b}$ in Fig. 7). It has also been found that the $\mathrm{V}_{\text {out }}$ signal is quite noisy for some values such as $130 \mathrm{kHz}$ and $1 \mathrm{~V}$ the applied from the signal generator 1 , $130 \mathrm{kHz}$ and $1.2 \mathrm{~V}$ the applied from the signal generator 2 (curve $\mathrm{c}$ in Fig. 7).

The output of the circuit was measured for different frequency and amplitude values of the applied sinusoidal signal and the best results were found to be around $100 \mathrm{kHz}$ and $1 \mathrm{~V}$. Figure 8 shows the circuit output signal obtained by using wires with lengths of 2, 4.5 and $7 \mathrm{~cm}$. Samples with a wire length of $2 \mathrm{~cm}$ show a linear output between the magnetic field values of approximately $\pm 250 \mathrm{~A} / \mathrm{m}$. The output signal varies between $\pm 0.31 \mathrm{~V}$. In this measurement of $2 \mathrm{~cm}$ wire, $110 \mathrm{kHz}$ and $1.2 \mathrm{~V}$ sinusoidal signal was applied to wire 1 , and $130 \mathrm{kHz}$ and $1.3 \mathrm{~V}$ sinusoidal signal was applied to wire 2 . The output signal ranged from $\pm 0.7 \mathrm{~V}$ on wires of $4.5 \mathrm{~cm}$ length and showed linearity in the magnetic field region of \pm 100 A / m. $115 \mathrm{kHz}$ and $1.3 \mathrm{~V}$ sine signal was applied to wire 1 , and $107 \mathrm{kHz}$ and $1.4 \mathrm{~V}$ sinusoidal signal was applied to wire 2 , in wire with $4.5 \mathrm{~cm}$ length. In the $7 \mathrm{~cm}$ long wires, the output signal showed linearity at lower magnetic field values, in this case, the signal with the values of $110 \mathrm{kHz}$ and $1.18 \mathrm{~V}$ was applied to the wire 1 and the signal with the values of $90 \mathrm{kHz}$ and $1.25 \mathrm{~V}$ to the 2 wire.

\section{Conclusions}


In this study, AGMI is created on amorphous ferromagnetic wires using micro magnets and a sensor that can accurately measure the magnetic field is developed with this feature.

It has been shown that it is possible to minimize output signal noise, hysteresis, offset shift and most importantly the linearity of the output signal by making small changes in the signal generator output voltage or frequency.

Samples with a wire length of $2 \mathrm{~cm}$ show a linear and zero hysteresis output between the magnetic field values of approximately $\pm 250 \mathrm{~A} / \mathrm{m}$ and the output signal varies between $\pm 0.31 \mathrm{~V}$. The output signal ranged from $\pm 0.6 \mathrm{~V}$ on wires of $7 \mathrm{~cm}$ length and showed linearity in the magnetic field region of $\pm 50 \mathrm{~A}$ / $\mathrm{m}$.

\section{References}

1. M.H. Phan, H.X. Peng, Mater. Sci. 53, 323 (2008).

2. M. Knobel, K. R. Pirota, J. Magn. Magn. Mater. 242, 33 (2002).

3. M. Vazquez, J. Magn. Magn. Mater. 226-230, 693 (2001).

4. L. Kraus, Sens. Actuators A Phys. 106, 187 (2003).

5. S.Q. Xiao, Y.H. Liu, S.S. Yan, Y.Y. Dai, L. Zhang, L.M. Mei, Phys. Rev. B, 61, 5734 (2000).

6. V.S.Kolat, N. Bayri, S. Michalik, T. Izgi, F.E. Atalay, H. Gencer, S. Atalay, J. Non Cryst. Solids, 355, 2562 (2009).

7. M. Knobel, M. Vazquez, L. Kraus, Elsevier, Amsterdam, pp. 497 (2003).

8. L.V. Panina, K. Mohri, Appl. Phys. Lett. 65, 1189 (1994).

9. M. Vazquez, M. Knobel, M.L. Sanchez, R. Valenzuela, A.P. Zhukov, Sens. Actuators A Phys. 59, 20 (1997).

10. K.R. Pirota, L. Kraus, M. Knobel, P.G. Pagliuso, C. Rettori, Phys. Rev. B, 9, 6685(1999).

11. L.V. Panina, K. Mohri, J. Magn. Magn. Mater. 157-158, 137 (1996).

12. R.S. Beach, A.E. Berkowitz, Appl. Phys. Lett. 64, 3652 (1994).

13. M. Vazquez, Y.F. Li, D.X. Chen, J. Appl. Phys. 91, 6539 (2002).

14. P. Aragoneses, A.P. Zhukov, J. Gonzalez, J.M. Blanco, L. Dominguez, Sens. Actuators, 81, 86 (2000).

15. S.K. Pal, A.K. Panda, M. Vazquez, A. Mitra, J. Mater. Process. Techn. 172, 182 (2006).

16. T. Uchiyama, K. Mohri, Y. Honkura, L.V. Panina, IEEE Trans. Magn. 48, 3833 (2012).

17. T. Wang, Y. Zhou, C. Lei, J. Luo, S. Xie, H. Pu, Biosens. Bioelectron. 90, 418 (2017).

18. C. Moron, C. Cabrera, A. Moron, A. García, M. Gonzalez, Sens. 15, 28340 (2015).

19. T. Uchiyama, S. Nakayama, K. Mohri, K. Bushida, Phys. Status Solidi A 206, 639 (2009).

20. K. Mohri, Y. Honkura, L.V. Panina, T. Uchiyama, J. Nanosci. Nanotech. 12, 7491 (2012). 
21. K. Mohri, F.B. Humphrey, L.V. Panina, Y. Honkura, J. Yamasaki, T. Uchiyama, M. Hirami, Phys. Status Solidi A 206, 601 (2009).

22. L.V. Panina, K. Mohri, D.P. Makhnovskiy, J. Appl. Phys. 85, 5444 (1999).

23. D.P. Makhnovskiy, L.V. Panina, D.J. Mapps, Appl. Phys. Lett. 77, 121 (2000).

24. X. Li, W.X. Lv, Y. Han, Q. Zhang, W.H. Xie, Q. Zhao, Z.J. Zhao, J. Alloys Comp. 730, 17 (2018).

25. P. Ciureanu, I. Khalil, L.G. C. Melo, P. Rudkowski, A. Yelon, J. Magn. Magn. Mater. 249, 305 (2002).

26. L. Kraus, M. Malatek, S.S. Yoon, C.G. Kim, J. Magn. Magn. Mater. 304, 214 (2006).

27. M.H. Phan, S.C. Yu, C.G. Kim, M. Vazquez, Appl. Phys. Lett. 83, 2871 (2003).

28. L.V. Panina, J. Magn. Magn. Mater. 249, 278 (2002).

29. A.S. Antonov, N.A. Buznikov, Techn. Phys. Lett. 42, 814 (2016).

30. J. Fan, N. Ning, J.B. Yi, L.S. Tan, X.P. Li, Phys. Scr. T, 139, 014076 (2010).

31. E.F. Silva, M. Gamino, A.M.H. Andrade, M.A. Correa, M. Vazquez, F. Bohn, App. Phys. Lett. 105, 102409. (2014).

32. J. Torrejon, M. Vazquez, L.V. Panina, J. Appl. Phys. 105, 033911 (2009).

33. T. Kitoh, K. Mohri, T. Uchiyama, IEEE Trans. Magn. 31, 3137 (1995).

34. S.H. Song, S.C. Yu, C.G. Kim, H.C. Kim, W.Y. Lim, J. Appl. Phys. 87, 5266 (2000).

35. G. Kim, K.J. Jang, H.C. Kim, S.S. Yoon, J. Appl. Phys. 85, 5447 (1999).

36. S.S. Yoon, P. Kollu, D.Y. Kim, G.W. Kim, Y. Cha, C.G. Kim, IEEE Trans. Magn. 45, 2727 (2009).

37. G. Yu, X. Bu, B. Yang, Y. Li, C. Xiang, IEEE Sens. J. 11, 2273 (2011).

38. P. Kollu, L. Jin, K.W. Kim, S.S. Yoon, C.G. Kim, Appl. Phys. A, 90, 533 (2008).

39. P.S. Traore, A. Asfour, J.P. Yonnet, C. Boudinet, Sens. Actuators A 271, 290 (2018).

40. M.M. Tehranchi, M. Ghanaatshoar, S.M. Mohseni, H. Eftekhari, J. Non Cryst. Solids, 354, 5175 (2008).

41. P. Kollu, S.S. Yoon, G.W. Kim, C.S. Angani, C.G. Ki, J. Magn. 15, 194 (2010).

42. S. Atalay, T. Izgi, N.A. Buznikov, V.S. Kolat, J. Magn. Magn. Mater. 453, 163 (2018).

43. N.A. Buznikov, S. Atalay, Mater. Res. Express, 5, 066107 (2018).

\section{Figures}




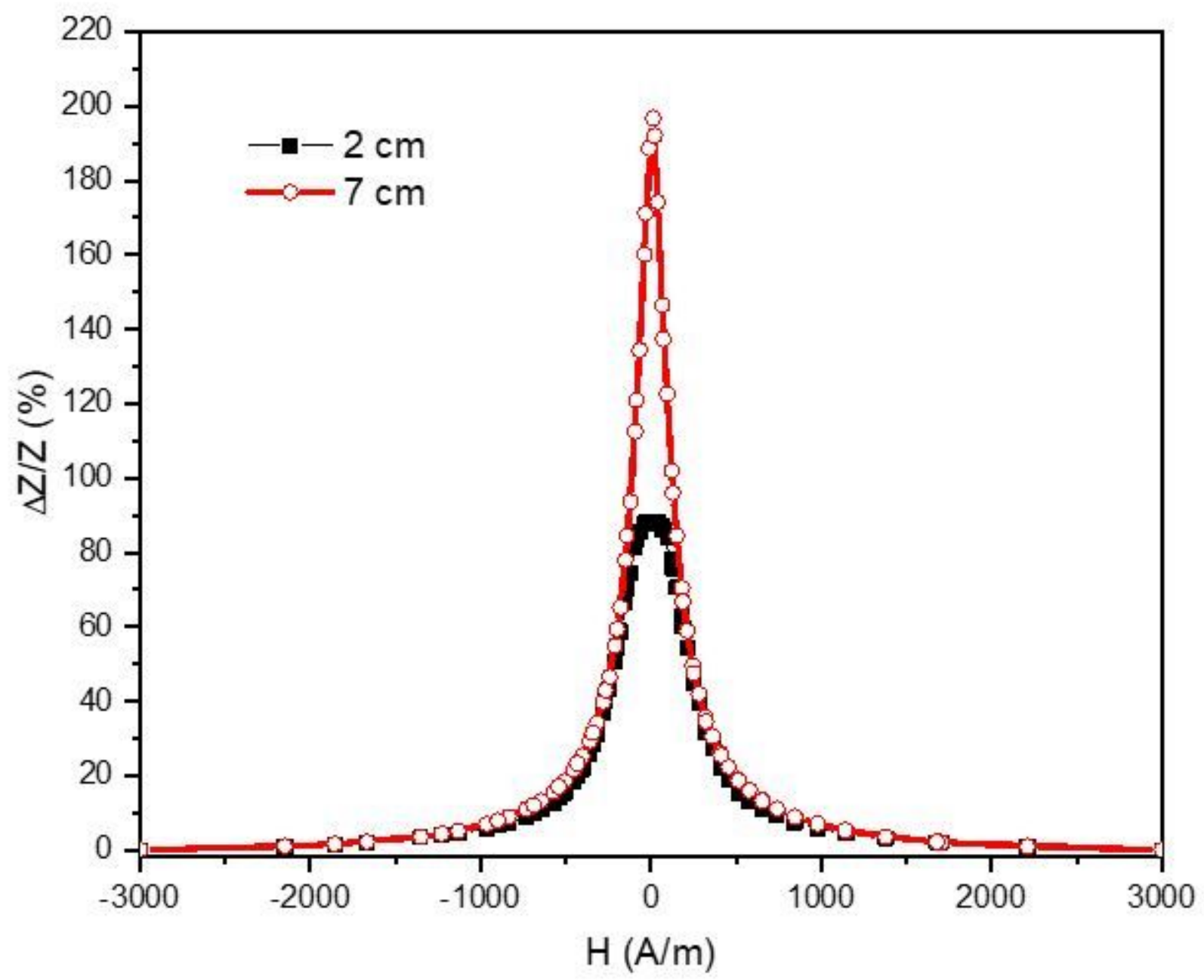

Figure 1

GMI curves of amorphous wire with 2 and $7 \mathrm{~cm}$ lengths at $100 \mathrm{kHz}$ driving current frequency. 


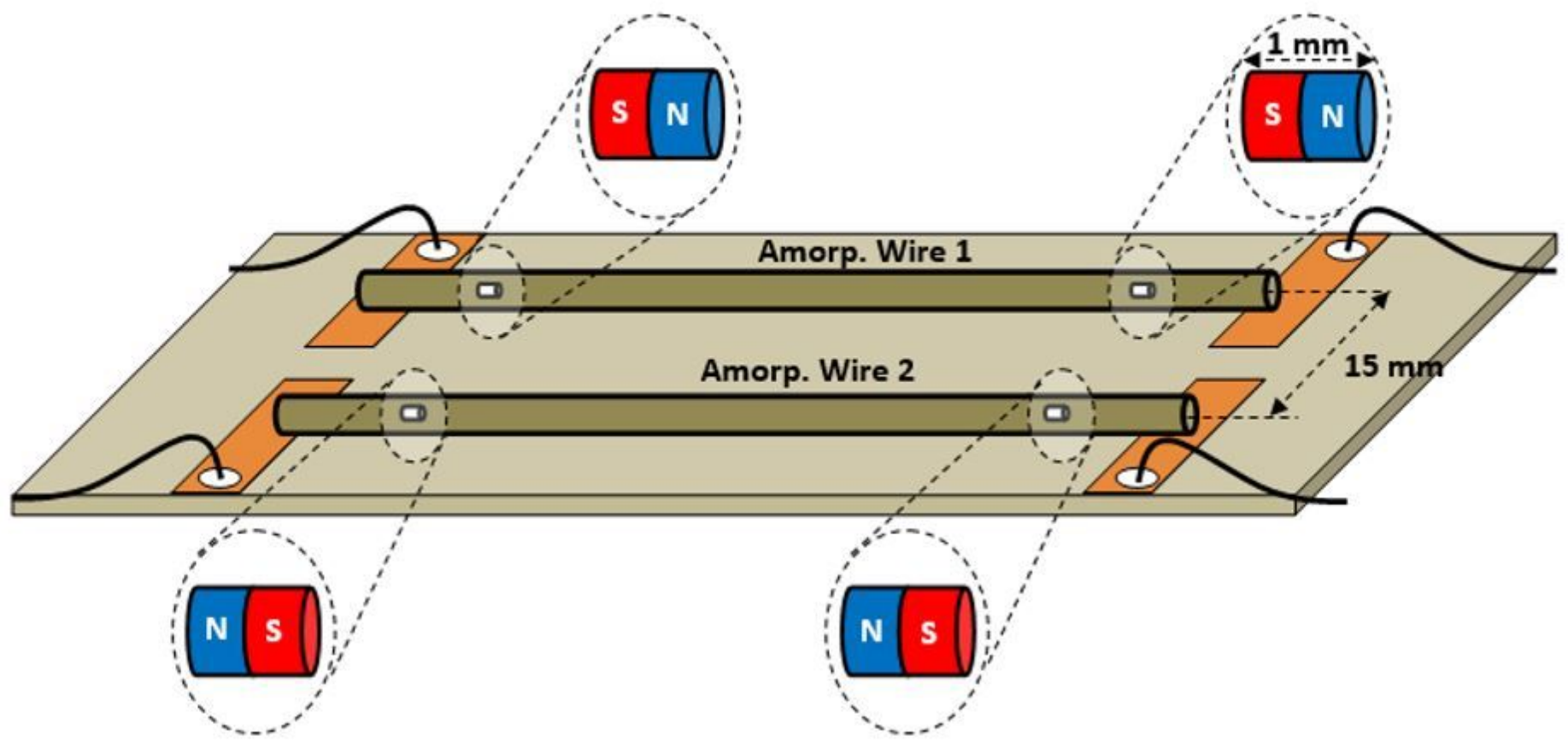

Figure 2

Schematic illustration of magnets positions placed on the surface of amorphous wires. 

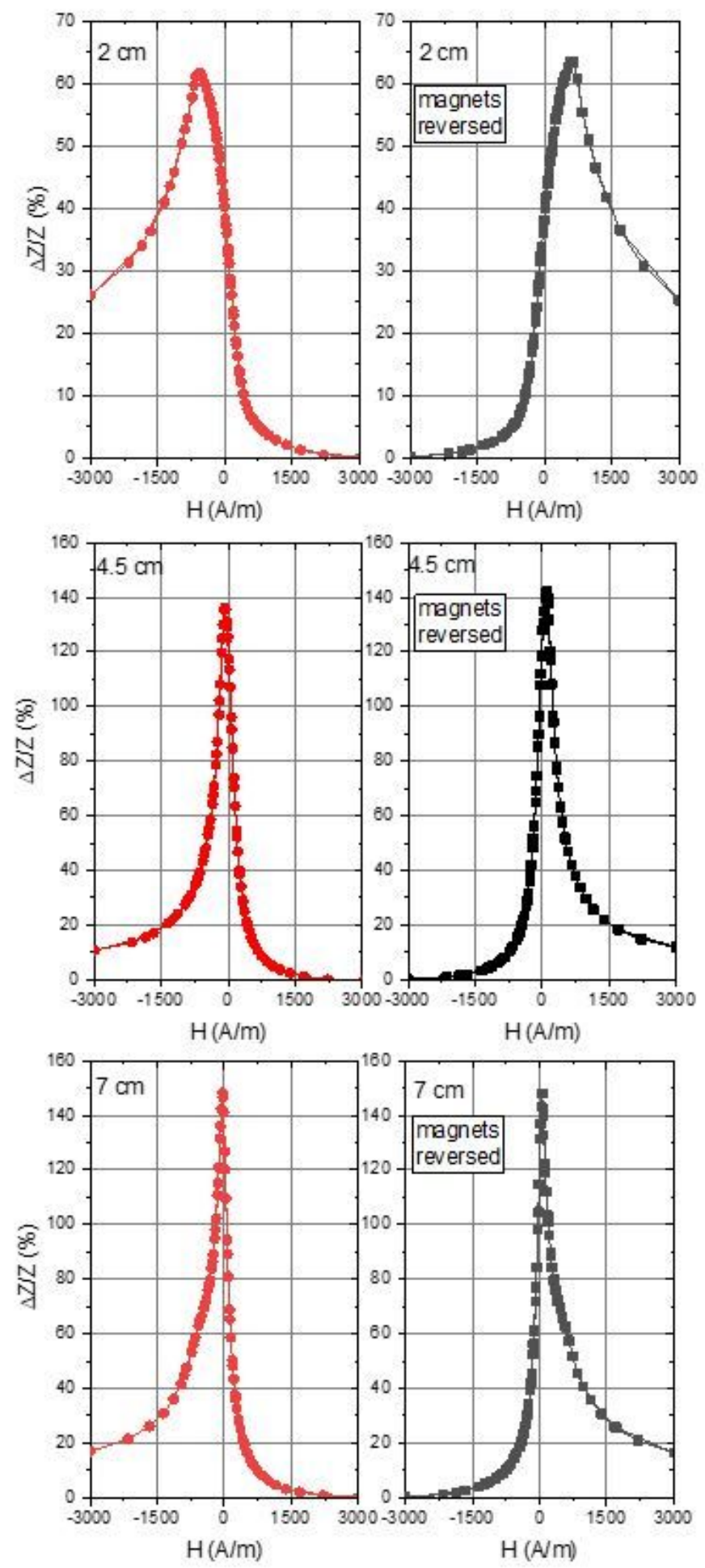

Figure 3

AGMI curves of wires with different lengths with two micro magnets. 


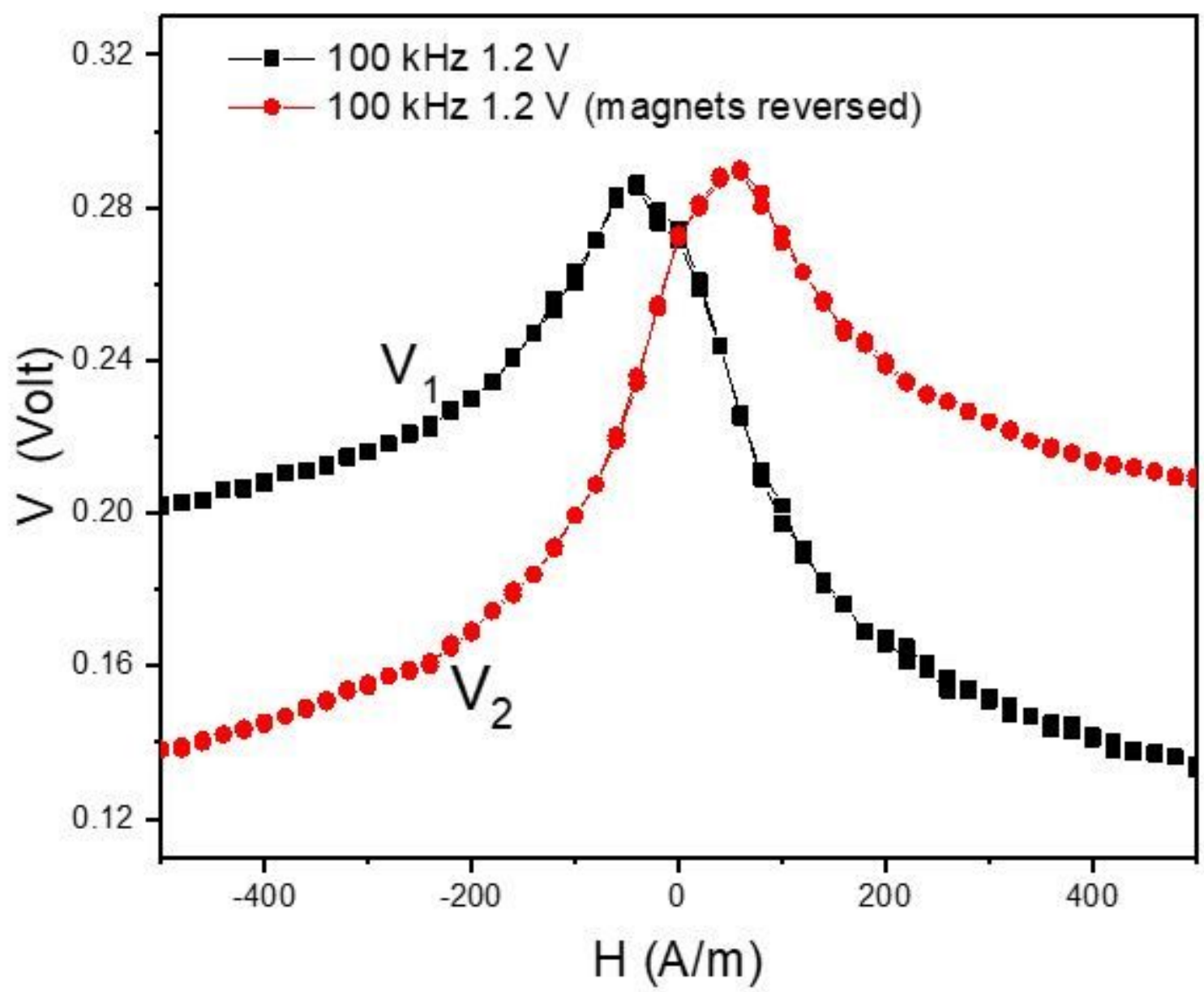

Figure 4

Peak detector output of AGMI curves for wire $7 \mathrm{~cm}$ long. 


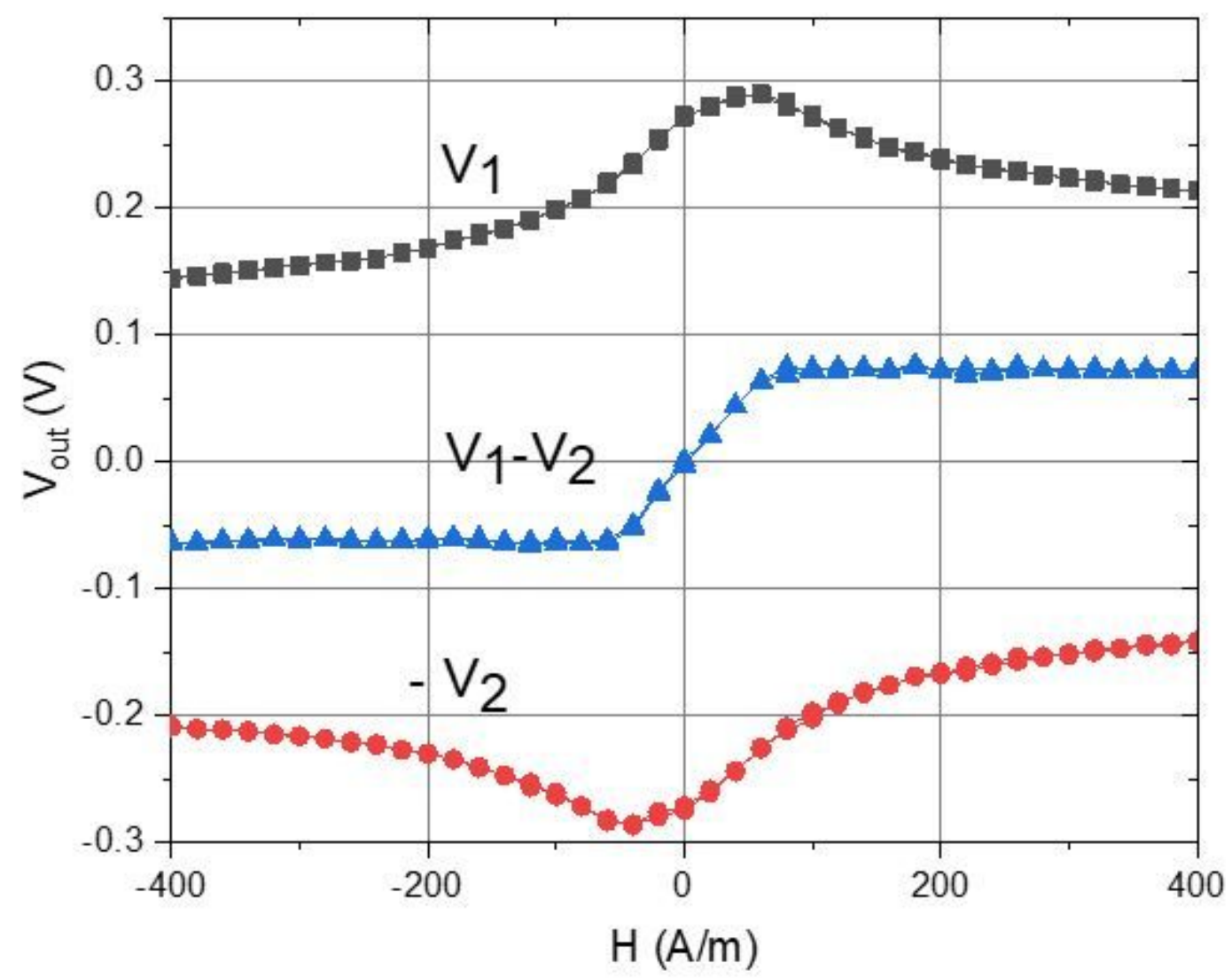

Figure 5

Principle of obtaining a linear sensor output. 


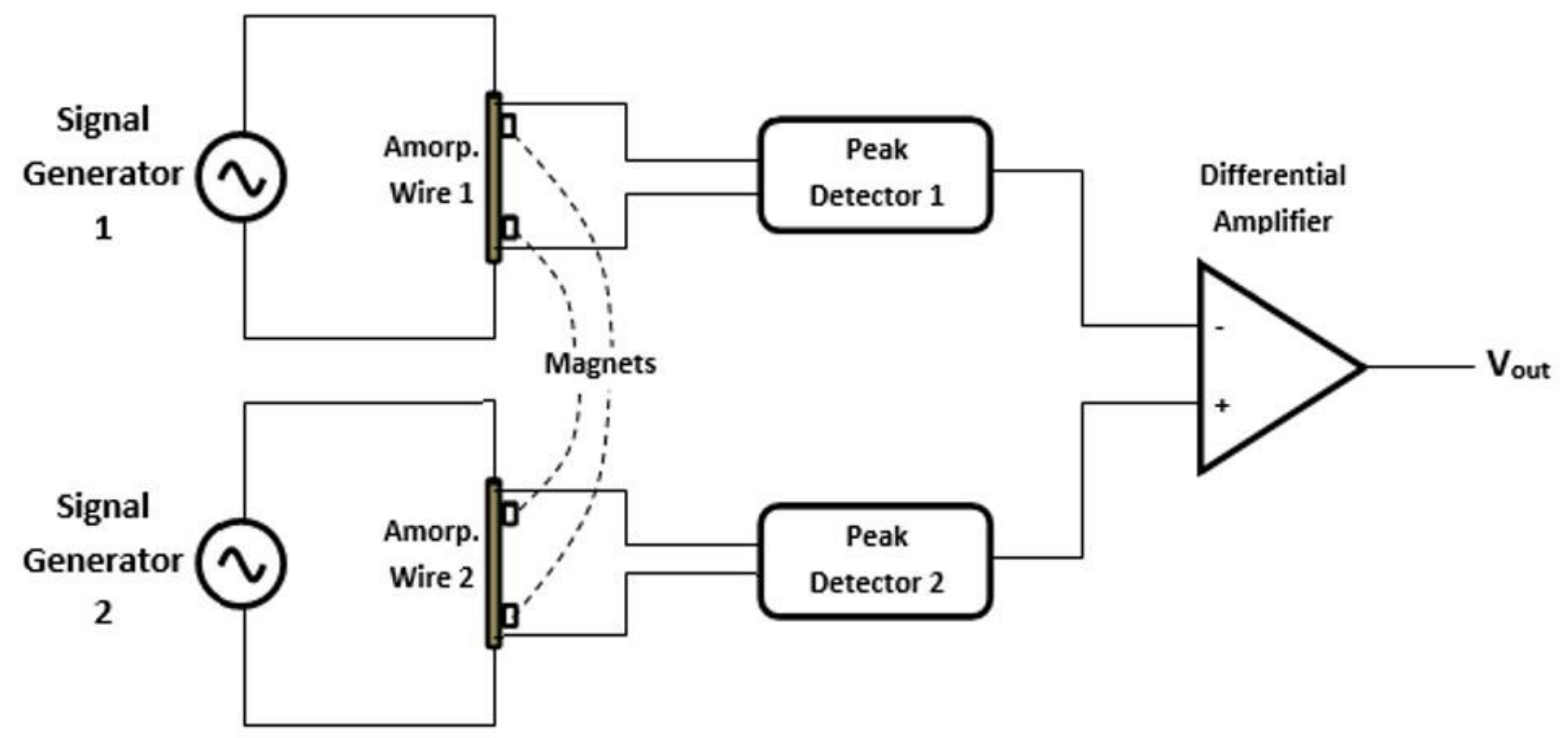

Figure 6

The circuit structure of AGMI magnetic field sensor. 


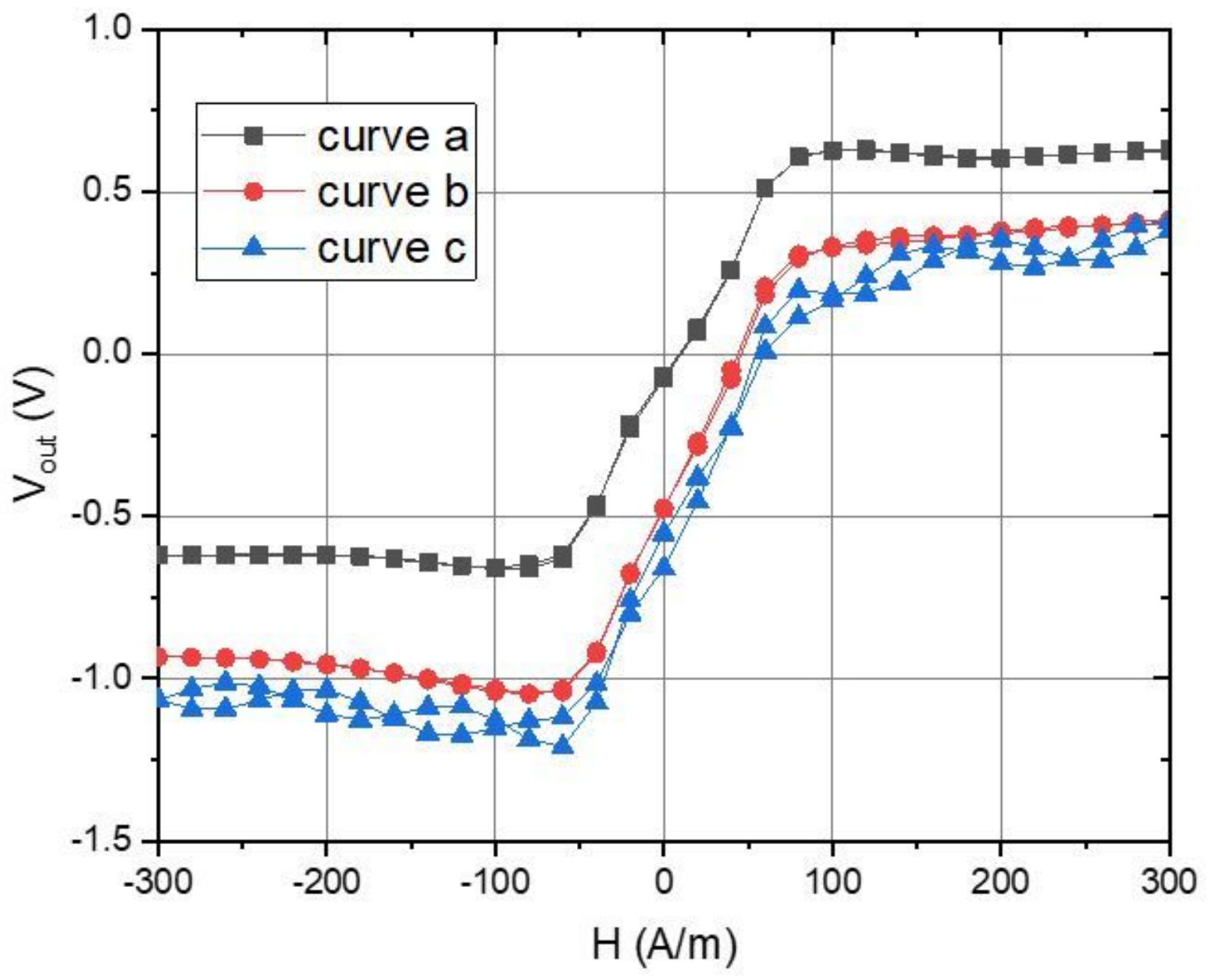

Figure 7

The output of the AGMI magnetic field sensor for various driving voltage amplitudes and frequencies for wire with $7 \mathrm{~cm}$ long. 


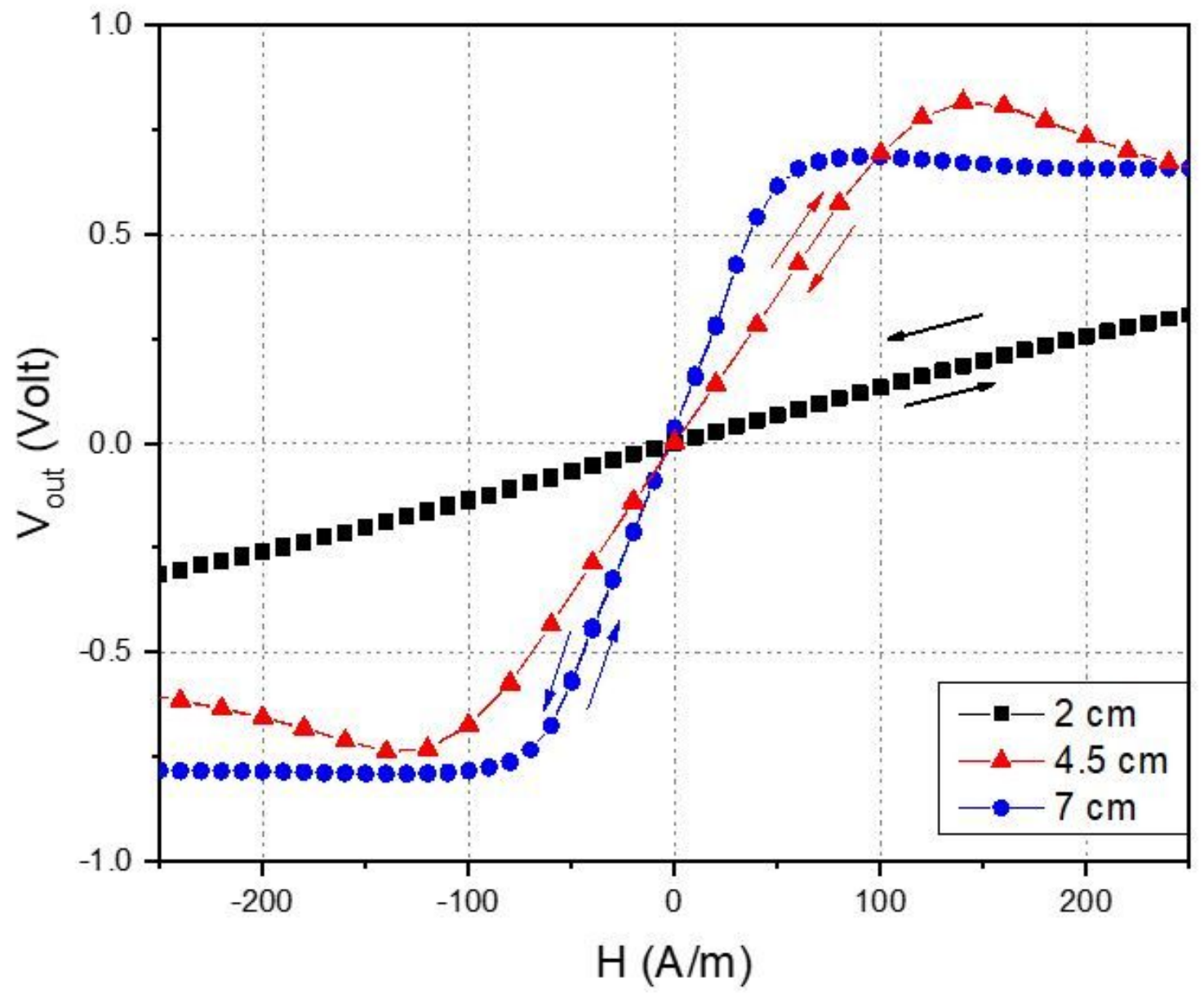

Figure 8

The output of the AGMI magnetic field sensor for wires with different lengths. 